\title{
Renin-angiotensin system inhibitors and mortality in patients with COVID-19
}

\author{
Luca Rossi ${ }^{1}$ - Alessandro Malagoli ${ }^{2}$ (1) - Andrea Biagi ${ }^{1}$ - Alessia Zanni ${ }^{1}$. Concetta Sticozzi ${ }^{1}$. Greta Comastri ${ }^{1}$. \\ Luigi Pannone ${ }^{3} \cdot$ Stefano Gandolf ${ }^{4} \cdot$ Pasquale Vergara $^{3} \cdot$ Giovanni Quinto Villani ${ }^{1}$
}

Received: 30 July 2020 / Accepted: 29 October 2020 / Published online: 22 November 2020

○) Springer-Verlag GmbH Germany, part of Springer Nature 2020

\begin{abstract}
Association of renin-angiotensin system inhibitors with risk of death in patients with hypertension (HTN) and coronavirus disease 2019 (COVID-19) is not well characterized. The aim of this study was to evaluate the outcomes of patients with HTN and COVID-19 with respect to different chronic antihypertensive drug intake. We performed a retrospective, observational study from a large cohort of patients with HTN and with a laboratory-confirmed severe acute respiratory syndrome coronavirus 2 infection admitted to the Emergency Rooms (ER) of the Piacenza Hospital network from February 21, 2020 to March 20, 2020. There were 1050 patients admitted to the ERs of the Piacenza Hospital network with COVID-19. HTN was present in 590 patients [median age, 76.2 years (IQR 68.2-82.6)]; 399 (66.1\%) patients were male. Of them, 248 patients were chronically treated with ACEi, 181 with ARBs, and 161 with other drugs (O-drugs) including beta blockers, diuretics and calcium-channel inhibitors. With respect to the antihypertensive use, there was no difference between comorbid conditions. During a follow-up of 38 days (IQR 7.0-46.0), 256 patients (43.4\%) died, without any difference stratifying for antihypertensive drugs. Of them, 107 (43.1\%) were in ACEi group vs 67 (37\%) in ARBs group vs 82 (50.7\%) in O-drugs group, (log-rank test: $p=0.066$ ). In patients with HTN and COVID-19, neither ACEi nor ARBs were independently associated with mortality. After adjusting for potential confounders in risk prediction, the rate of death was similar. Our data confirm Specialty Societal recommendations, suggesting that treatment with ACEIs or ARBs should not be discontinued because of COVID-19.
\end{abstract}

Keywords COVID-19 $\cdot$ SARS-CoV-2 $\cdot$ Renin-angiotensin system (RAS) inhibitors $\cdot$ Mortality $\cdot$ Hypertension

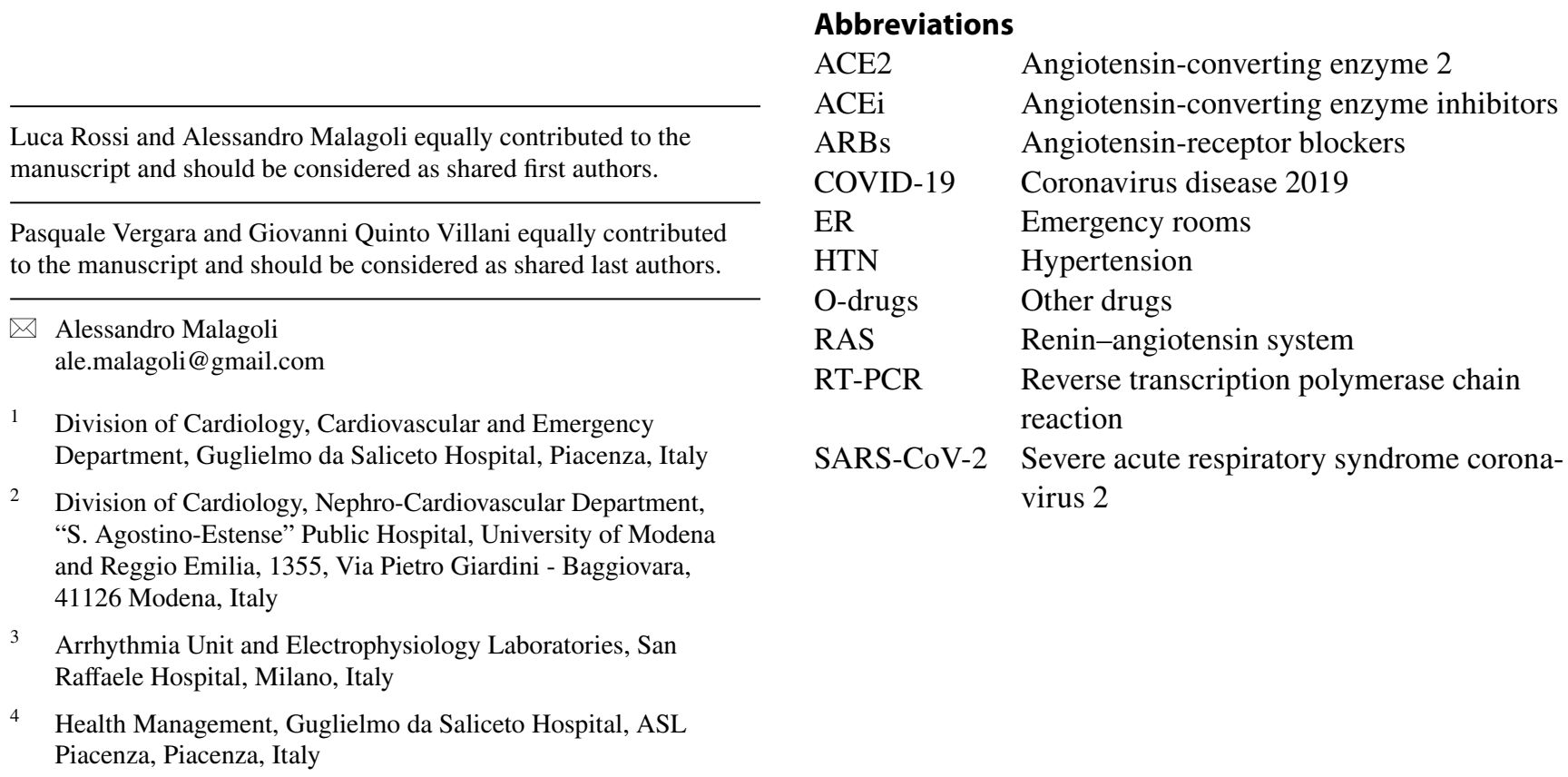




\section{Introduction}

In late December 2019, the coronavirus disease 2019 (COVID-19) caused by a novel coronavirus, severe acute respiratory syndrome coronavirus 2 (SARS-CoV-2), was described for the first time in Wuhan, China [1]. Quickly spreading all over the world, it was declared a pandemic infection by the World Health Organization on March 11, 2020 [2]. The clinical spectrum of COVID-19 appeared to be wide, encompassing asymptomatic infection, mild upper respiratory tract illness and acute respiratory distress syndrome, with a high mortality rate [3, 4]. It remains unclear whether the reported mortality was related to the chronical use of renin-angiotensin system (RAS) inhibitors. Angiotensin-Converting Enzyme inhibitors (ACEi) and Angiotensin-Receptor Blockers (ARBs) are a group of pharmaceuticals that have different effects on angiotensin II, the primary substrate of the angiotensin-converting enzyme 2 (ACE2), commonly applied in the treatment of hypertension (HTN). The potential bridge between SARS-CoV-2 pathophysiology and ACEi/ARBs effects derives from evidences showing that SARS-CoV-2 uses ACE2 receptor to enter in human alveolar epithelial cells [5]. ACE2 is a homologue of ACE, widely distributed in the heart, kidneys and lungs, and it functions as a negative regulator of the RAS. Use of ACEIs and ARBs might upregulate ACE2 expression, thus increasing patient susceptibility to viral host cell entry. The purpose of the present study was to evaluate the association of ACEi and ARBs with risk of death in patients with HTN and COVID-19.

\section{Methods}

\section{Study design and population}

This was a retrospective observational study performed at Piacenza Hospital Network, including 3 Hospitals in Piacenza Province, Italy ('Guglielmo da Saliceto' Piacenza Hospital, Castel San Giovanni Hospital and Fiorenzuola d'Arda Hospital); the Hospital network is referral for 287 152 inhabitants. All consecutive patients with laboratoryconfirmed COVID-19 infection admitted to the Emergency Rooms (ER) of the Piacenza Hospital network from February 21, 2020 to March 20, 2020 and HTN were enrolled in the study. Clinical investigations were conducted according to the principles of the Declaration of Helsinki. The study was approved by the Institutional Ethical Board of the "Emilia Nord Area" (Approval number 2020/0029787); written informed consent was waived by the Ethics Commission due to the emergency of the infectious disease.
Positive laboratory test for SARS-Cov-2 infection was defined as a result of real-time reverse transcription polymerase chain reaction (RT-PCR) assay of nasal and pharyngeal swabs [6]. The exam was implemented in a local laboratory with the adjunct of RT-PCR assays. Patients with HTN were classified based upon documented medical history with systolic blood pressure $\geq 140 \mathrm{mmHg}$ or diastolic blood pressure $\geq 90 \mathrm{mmHg}$ [7].

\section{Data collection}

Clinical data are routinely collected during ER access and hospitalization in Piacenza Hospital network on a shared electronic medical record. Deaths in Piacenza Province are collected on a daily basis from the "Azienda Sanitaria Locale" (Local Health Authority) and recorded on an electronic survival record. Clinical data were extracted from the electronic medical records and merged with the survival data provided by the Azienda Sanitaria Locale by members of the research team; data were carefully reviewed and confirmed by two independent researchers to guarantee the accuracy of the data extraction procedures. Patients were followed up from the index date and until 1 of the following: outcome occurrence or end of study period (April 24, 2020). The endpoint of the study was death for any cause.

\section{Statistical methods}

Due to the retrospective nature of the study, no sample size calculation was a priori performed; sample size was equal to patients admitted to ERs of the Piacenza Hospital network. Continuous variables are expressed as mean \pm standard; the independent samples t-test or Mann-Whitney $U$-test was used to compare normally and non-normally distributed continuous variables between survivors and non-survivors. Categorical variables are summarized as frequency and percentage, and compared using Pearson's $\chi^{2}$ exact test. ANOVA and Bonferroni post hoc test for multiple comparisons were performed to estimate differences between groups stratified by the antihypertensive drug treatment. Antihypertensive drug categories included in the analysis were ACEi group, ARBs group and other drugs (O-drugs) group, and were defined as use of these drugs. O-drugs included beta blockers, calcium-channel blockers, alfa-blockers and diuretics.

Cox regression model was performed to identify risk/ protective factors for death of the clinical covariates. Kaplan-Meier survival curves were used to estimate freedom from death. Log-rank test was used to compare survival times of patients stratified by the antihypertensive drug treatment. Propensity score-matched cohorts were created based on significant predictors in the previously developed Cox regression model. Patients on ACEi/ARBs/O-drugs were paired according to the propensity scores with nearest 
matching and a ratio of 1:1:1. The balance of covariates was evaluated by estimating standardized differences before and after matching, and small absolute value less than 0.25 was considered successful balancing between the groups. Malignancies included active neoplasia and history of any previous neoplasia; cardiovascular disease included cardiomyopathy and heart failure. Analyses regarding different factors were based on non-missing data. Analyses were performed using SPSS statistical software version 23.0 (IBM SPSS); significance level was set at 0.05 .

\section{Results}

\section{Patients characteristics}

As of February 21, 2020 to March 20, 2020, 1,050 consecutive patients with confirmed SARS-CoV2 infection were admitted to the ERs of Piacenza Hospital network. Among these patients, a total of 603 had a history of HTN. After excluding 13 patients without available key information in their medical records, we included 590 patients in the final analysis. Clinical data of patients are shown in Table 1. The median age was 76.2 years (IQR 68.2-82.6) ranging from 33.8 to 98.5 years; 399 (66.1\%) were male. 90 (15.2\%) were discharged from the ER and treated in the outpatient setting. 500 (84.8\%) were admitted into the hospital: of these patients, 84 patients $(14.2 \%)$ have had access to the intensive care unit and $133(22.5 \%)$ were admitted in semiintensive care units. The median time from illness onset to hospital admission was 7 days (IQR 3-10). One-third of the patients required respiratory support with invasive mechanical ventilation $(76,12.9 \%)$ or with non-invasive ventilation $(119,19.2 \%)$. Non-survivor patients were older [72.9 years old (IQR 64.1-80.2) vs 79.5 years old (IQR 73.9-84.8), $p<0.001]$ and showed more comorbidities compared to survivors. Moreover, a greater female sex prevalence was observed in survivor patients ( $63.5 \%$ vs $73.0 \%, p=0.01)$.

\section{Characteristics of antihypertensive drug treatment groups}

248 (42.0\%) patients chronically used ACEi, 181 (30.7\%) ARBs, and 161 (27.3\%) O-drugs; their clinical data are shown in Table 2. Users of ACEi/ARBs trended to be younger than non-users (75.6 years [IQR 66.8-81.3] vs 76.6 years [IQR 69.7-84.6] and were more often men than non-users. Underlying diseases were present in nearly half of patients, with hyperlipidemia being the most common, followed by diabetes, cardiovascular disease, chronic kidney disease and stroke. As a result, $240(40.7 \%)$ patients had 3 or more coexisting medical conditions, without significant differences between groups.
The most common self-reported symptoms at onset of illness were fever and dyspnea, followed by cough, and fatigue; less common symptoms were diarrhea, sensory taste disturbances, sputum production, and headache. More than half of patients $(60.7 \%)$ developed dyspnea. Symptoms were not different between groups. COVID-19 severity was classified according with the guidelines on the Diagnosis and Treatment of COVID-19 [8] and defined as severe with the presence of one of the following conditions: respiratory failure that require mechanical ventilation, shock or multi-organ dysfunction. Critical clinical conditions were not different between groups.

\section{Outcome analysis}

At the end of the study period, 228 (38.6\%) patients were discharged, $16(2.7 \%)$ patients were still hospitalized, and $256(43.4 \%)$ patients died. All 90 patients treated in the outpatient setting were alive. The median time from illness onset to death was 12.5 days (IQR 4.5-16.0). In Cox proportional hazard modeling, age (hazard ratio: 1.059; $95 \%$ confidence interval: $1.045-1.073 ; p<0.001)$ and gender (hazard ratio: 0.699; 95\% confidence interval: 0.531-0.922; $p=0.011$ ) were associated with death; likewise, the $\mathrm{PaO} 2 /$ $\mathrm{FiO} 2$, the respiratory rate, $\mathrm{LDH}$ and PCR serum levels were found strong mortality predictors. Chronic intake of various antihypertensive drug treatments was not associated with risk of death. None of the comorbidities was related with mortality, whereas the coexistence of 3 or more underlying diseases was a predictor of mortality (Table 3). No significant differences in mortality were found between groups (log-rank test: $p=0.066$ ). Mortality was $43.1 \%$ among ACEi users, $37.0 \%$ among ARBs users, and 50.9\% among patients using any other antihypertensive drug, with a hint at possible longer survival in patients on ACEi or ARBs treatment (Fig. 1). We conducted a propensity score-matched analysis to account for unbalances in the following variables: age, gender, diabetes and chronic kidney disease. 159 patients on ACEi were successfully matched with 163 patients on ARBs and 149 on O-Drugs. After matching, no significant differences in mortality were found between ACEi, ARBs, and O-drugs groups (log-rank test: $p=0.102)$. Kaplan-Meier curve for the three drug treatments after matching is shown in Fig. 2.

\section{Discussion}

In the current study, data showed that RAS inhibitors were not associated with an increased mortality of COVID-19 in patient with HTN.

As China has firstly experienced the outbreak of COVID-19, the current available epidemiological data 
Table 1 Characteristics of patients with hypertension and COVID-19

\begin{tabular}{|c|c|c|c|c|}
\hline & $\begin{array}{l}\text { All population } \\
n=590\end{array}$ & $\begin{array}{l}\text { Survivors } \\
n=334\end{array}$ & $\begin{array}{l}\text { Non survivors } \\
n=256\end{array}$ & $p$ value \\
\hline Age—median (IQR) (years) & $76.2(68.2-82.6)$ & $72.9(64.1-80.2)$ & $79.5(73.9-84.8)$ & $<0.001$ \\
\hline Male gender no. $(\%)$ & $399(67.6)$ & $212(63.5)$ & $187(73.0)$ & 0.014 \\
\hline \multicolumn{5}{|l|}{ Chronic disease } \\
\hline Cardiovascular disease-no. (\%) & $95(16.1)$ & $50(15.0)$ & $45(17.6)$ & 0.393 \\
\hline Hyperlipidemia-no. (\%) & $205(34.7)$ & $113(33.8)$ & $92(35.9)$ & 0.595 \\
\hline Diabetes-no. $(\%)$ & $137(23.2)$ & $70(21.0)$ & $67(26.2)$ & 0.137 \\
\hline Atrial fibrillation-no. $(\%)$ & $101(17.1)$ & $49(14.7)$ & $52(20.3)$ & 0.071 \\
\hline COPD—no. $(\%)$ & $121(20.5)$ & $69(20.7)$ & $52(20.3)$ & 0.918 \\
\hline CKD—no. (\%) & $90(15.3)$ & $32(9.6)$ & $58(22.7)$ & $<0.001$ \\
\hline Stroke-no. $(\%)$ & $21(3.6)$ & $8(2.4)$ & $13(5.1)$ & 0.081 \\
\hline Malignancy-no. (\%) & $47(8.0)$ & $23(6.9)$ & $24(9.4)$ & 0.269 \\
\hline 3 or more comorbidities-no. $(\%)$ & $240(40.7)$ & $124(37.1)$ & $116(45.3)$ & 0.045 \\
\hline \multicolumn{5}{|l|}{ Respiratory support } \\
\hline OTI-no. $(\%)$ & $76(12.9)$ & $47(14.1)$ & $29(11.3)$ & 0.324 \\
\hline NIV-no. $(\%)$ & $113(19.2)$ & $37(11.1)$ & $76(29.7)$ & $<0.001$ \\
\hline \multicolumn{5}{|l|}{ Symptoms at onset of illness } \\
\hline Fever-no. $(\%)$ & $450(76.3)$ & $231(69.1)$ & $219(85.5)$ & 0.550 \\
\hline Cough—no. $(\%)$ & $227(38.5)$ & $138(41.3)$ & $89(34.8)$ & 0.001 \\
\hline Dyspnea-no. (\%) & $358(60.7)$ & $171(51.2)$ & $187(73.0)$ & 0.058 \\
\hline Diarrhea-no. $(\%)$ & $37(6.3)$ & $26(7.8)$ & $11(4.3)$ & 0.010 \\
\hline \multicolumn{5}{|l|}{ Vital signs at admission } \\
\hline Temperature $\left({ }^{\circ} \mathrm{C}\right)$-median (IQR) & $37.5(36.8-38.3)$ & $37.4(36.8-38.2)$ & $37.5(36.7-38.3)$ & 0.934 \\
\hline $\mathrm{SBP}(\mathrm{mmHg})$-median (IQR) & $130.0(115.0-145.0)$ & $130.0(120.0-147.5)$ & $130(113.5-145.0)$ & 0.394 \\
\hline $\mathrm{PaO} 2 / \mathrm{FiO} 2-\operatorname{median}(\mathrm{IQR})$ & $238.1(152.4-290.5)$ & $263.9(211.3-302.3)$ & $200.0(112.9-279.4)$ & $<0.001$ \\
\hline $\mathrm{PaO} 2 / \mathrm{FiO} 2<300$-no. $(\%)$ & $375(63.3)$ & $164(49.1)$ & $211(82.8)$ & $<0.001$ \\
\hline \multicolumn{5}{|l|}{ Laboratory parameters-median (IQR) } \\
\hline Serum creatinine $(\mathrm{mg} / \mathrm{dL})$ & $1.1(0.9-1.6)$ & $1.0(0.9-1.3)$ & $1.3(1.0-1.8)$ & $<0.001$ \\
\hline LDH (U/L) & $413.0(305.0-537.0)$ & $385.0(297.0-486.0)$ & $462.0(338.0-601.5)$ & $<0.001$ \\
\hline C-reactive protein $(\mathrm{mg} / \mathrm{dL})$ & $11.3(5.8-17.5)$ & $9.9(5.0-15.5)$ & $12.9(7.2-19.3)$ & $<0.001$ \\
\hline Hemoglobin (g/dL) & $13.4(12.0-14.7)$ & $13.6(12.5-14.8)$ & $13.1(11.6-14.6)$ & 0.025 \\
\hline White blood cell count $\left(10^{3} / \mathrm{L}\right)$ & $6.9(5.2-9.3)$ & $6.6(5.0-8.9)$ & $7.2(5.6-10.1)$ & 0.019 \\
\hline Lymphocytes (\%) & $11.9(6.4-17.9)$ & $13.4(7.8-19.3)$ & $9.7(5.4-16.6)$ & $<0.001$ \\
\hline \multicolumn{5}{|l|}{ Pneumonia classification } \\
\hline COVID severe-no. $(\%)$ & $229(38.8)$ & $40(12.0)$ & $189(73.8)$ & $<0.001$ \\
\hline Curb 65 severe-no. $(\%)$ & $100(16.9)$ & $44(13.2)$ & $56(21.9)$ & 0.005 \\
\hline qSOFA severe-no. (\%) & $59(10.0)$ & $39(11.7)$ & $20(7.8)$ & 0.121 \\
\hline
\end{tabular}

$I Q R$, interquartile range, $C O P D$ chronic obstructive pulmonary disease, $C K D$ chronic kidney disease, $O T I$ orotracheal intubation, $N I V$ non-invasive ventilation, $S B P$ systolic blood pressure, $\mathrm{PaO} 2 / \mathrm{FiO} 2$ partial pressure of oxygen in arterial blood/fraction of inspired oxygen, $\mathrm{LDH}$ lactate dehydrogenase, $q S O F A$ quick sequential organ failure assessment

concern the Chinese population [9]. Of interest, HTN was the most frequent coexisting condition, with an estimated prevalence of $15 \%$; however, data from PEACE Million Persons Project showed that nearly half of Chinese adults are suffering from HTN [10]. In contrast to these findings, the prevalence of HTN in our data is significantly higher, reflecting the real rate of HTN in the general population.
Recently, uncertainties have been raised on the use antihypertensive drugs that modulate the RAS in patient at risk for COVID-19; it has been suggested that they could act as a potential risk factor for poor outcome in COVID-19 patients by up-regulating ACE2. The importance of RAS in the mechanisms that cause HTN and determine its prognosis is well established. Angiotensin II is the principal mediator 
Table 2 Clinical characteristics of patients on treatment with ACEi, ARBs and other drugs

\begin{tabular}{|c|c|c|c|c|}
\hline & $\begin{array}{l}\text { ACEi } \\
n=248\end{array}$ & $\begin{array}{l}\text { ARBs } \\
n=181\end{array}$ & $\begin{array}{l}\text { O-drugs } \\
n=161\end{array}$ & $p$ value \\
\hline Age-median (IQR) (years) & $76.3(68.8-82.7)$ & $75.2(66.8-81.3)$ & $76.6(69.7-84.6)$ & 0.080 \\
\hline Male gender no. $(\%)$ & $187(75.4)$ & $120(66.3)$ & $92(57.1)$ & 0.001 \\
\hline \multicolumn{5}{|l|}{ Chronic disease } \\
\hline Cardiovascular disease-no. (\%) & $43(17.3)$ & $23(12.7)$ & $29(18.0)$ & 0.323 \\
\hline Hyperlipidemia-no. (\%) & $86(34.7)$ & $70(38.7)$ & $49(30.4)$ & 0.279 \\
\hline Diabetes-no. $(\%)$ & $63(25.4)$ & $47(26.0)$ & $27(16.8)$ & 0.075 \\
\hline Atrial fibrillation-no. (\%) & $45(18.1)$ & $31(17.1)$ & $25(15.5)$ & 0.790 \\
\hline COPD—no. $(\%)$ & $40(16.1)$ & $47(26.0)$ & $34(21.1)$ & 0.044 \\
\hline CKD-no. $(\%)$ & $41(16.5)$ & $25(13.8)$ & $24(14.9)$ & 0.734 \\
\hline Stroke-no. $(\%)$ & $11(4.4)$ & $6(3.3)$ & $4(2.5)$ & 0.569 \\
\hline Malignancy-no. (\%) & $22(8.9)$ & $13(7.2)$ & $12(7.5)$ & 0.784 \\
\hline 3 or more comorbidities-no. $(\%)$ & $101(40.7)$ & $78(43.1)$ & $61(37.9)$ & 0.620 \\
\hline \multicolumn{5}{|l|}{ Respiratory support } \\
\hline OTI-no. $(\%)$ & $34(13.7)$ & $22(12.2)$ & $20(12.4)$ & 0.875 \\
\hline NIV—no. $(\%)$ & $50(20.2)$ & $39(21.5)$ & $24(14.9)$ & 0.258 \\
\hline \multicolumn{5}{|l|}{ Symptoms at onset of illness } \\
\hline Fever-no. $(\%)$ & $188(75.8)$ & $137(75.7)$ & $125(77.6)$ & 0.243 \\
\hline Cough-no. (\%) & $105(42.3)$ & $67(37.0)$ & $55(34.2)$ & 0.105 \\
\hline Dyspnea-no. (\%) & $159(64.1)$ & $108(59.7)$ & $91(56.5)$ & 0.194 \\
\hline Diarrhea-no. $(\%)$ & $17(6.9)$ & $9(5.0)$ & $11(6.8)$ & 0.648 \\
\hline \multicolumn{5}{|l|}{ Vital signs at admission } \\
\hline Temperature $\left({ }^{\circ} \mathrm{C}\right)$-median (IQR) & $37.7(36.9-38.4)$ & $37.3(36.6-38.0)$ & $37.5(37.0-38.1)$ & 0.149 \\
\hline $\mathrm{SBP}(\mathrm{mmHg})$-median (IQR) & $130.0(117.5-150.0)$ & $125.0(114.5-138.0)$ & $127.5(115.0-144.0)$ & 0.045 \\
\hline $\mathrm{PaO} 2 / \mathrm{FiO} 2$-median (IQR) & $223.5(151.8-281.5)$ & $226.4(167.3-290.5)$ & $257.1(137.6-304.0)$ & 0.258 \\
\hline $\mathrm{PaO} 2 / \mathrm{FiO} 2<300-$ no. $(\%)$ & $168(67.7)$ & $114(63.0)$ & $93(57.8)$ & 0.120 \\
\hline \multicolumn{5}{|l|}{ Laboratory parameters-median (IQR) } \\
\hline Serum creatinine $(\mathrm{mg} / \mathrm{dL})$ & $1.1(0.9-1.6)$ & $1.2(0.9-1.5)$ & $1.1(0.9-1.7)$ & 0.219 \\
\hline LDH (U/L) & $425.0(314.5-540.0)$ & $437.0(326.5-574.8)$ & $364.5(288.8-482.0)$ & 0.009 \\
\hline C-reactive protein (mg/dL) & $10.9(5.7-16.8)$ & $12.0(6.2-18.4)$ & $10.9(5.4-18.5)$ & 0.301 \\
\hline Hemoglobin (g/dL) & $13.4(12.1-14.9)$ & $13.6(12.4-14.7)$ & $13.2(11.8-14.5)$ & 0.371 \\
\hline White blood cell count $\left(10^{3} / \mathrm{L}\right)$ & $6.7(5.2-9.2)$ & $7.3(5.5-10.0)$ & $6.7(5.2-8.8)$ & 0.143 \\
\hline Lymphocytes (\%) & $12.6(5.7-18.4)$ & $11.6(6.7-16.7)$ & $11.3(6.7-17.9)$ & 0.683 \\
\hline \multicolumn{5}{|l|}{ Pneumonia classification } \\
\hline Covid severe-no. $(\%)$ & 99 (39.9) & $72(39.8)$ & $58(36.0)$ & 0.696 \\
\hline Curb 65 severe-no. (\%) & $43(17.3)$ & 29 16.0) & $28(17.4)$ & 0.923 \\
\hline qSOFA severe-no. (\%) & $32(12.9)$ & $14(7.7)$ & $13(8.1)$ & 0.134 \\
\hline
\end{tabular}

$A C E i$ angiotensin-converting enzyme inhibitors, $A R B s$ angiotensin-receptor blockers, $I Q R$ interquartile range, $C O P D$ chronic obstructive pulmonary disease, $C K D$ chronic kidney disease, $O T I$ orotracheal intubation, NIV non-invasive ventilation, $S B P$ systolic blood pressure, $P a O 2 /$ $\mathrm{FiO} 2$ partial pressure of oxygen in arterial blood/fraction of inspired oxygen, $L D H$ lactate dehydrogenase, qSOFA quick sequential organ failure assessment

of RAS. ACEi and ARBs are the major classes of RAS inhibitors and have been proved to reduce cardiovascular mortality $[11,12]$. Both classes of drugs block the actions of angiotensin II and interact with ACE2 by different mechanisms. ACE2 has been found to be protective in a number of different lung injury models and it seems reasonable that RAS inhibitors should increase ACE2 level in human lungs $[13,14]$. SARS-CoV-2 interfaces with RAAS through ACE2
[15]. It has been shown that SARS-CoV-2 uses ACE2 for entry into target cells [16]. Moreover, SARS-CoV-2 spike protein binding to ACE2 downmodulates ACE2 expression, and loss of ACE2 expression results in excessive production of angiotensin. Given the dual possible role of ACE2 in COVID-19, two opposite hypotheses were formulated: the first emphasizes the ability of SARS-CoV-2 to use ACE2 for entry into target cells. On the basis of this detrimental effect, 
Table 3 Cox regression analysis of factors associated with mortality

\begin{tabular}{|c|c|c|c|}
\hline & HR & $95 \% \mathrm{CI}$ & $p$ value \\
\hline Age & 1.059 & $1.045-1.073$ & $<0.001$ \\
\hline Gender & 0.699 & $0.531-0.922$ & 0.011 \\
\hline \multicolumn{4}{|l|}{ Vital signs at admission } \\
\hline Temperature & 0.990 & $0.870-1.126$ & 0.882 \\
\hline $\mathrm{PaO} 2 / \mathrm{FiO} 2$ & 0.995 & $0.994-0.997$ & $<0.001$ \\
\hline $\mathrm{PaO} 2 / \mathrm{FiO} 2<300$ & 3.519 & $2.549-4.859$ & $<0.001$ \\
\hline \multicolumn{4}{|l|}{ Laboratory parameters } \\
\hline $\mathrm{LDH}$ & 1.001 & $1.000-1.001$ & $<0.001$ \\
\hline C-reactive protein & 1.018 & $1.011-1.025$ & $<0.001$ \\
\hline White blood cell count & 1.044 & $1.015-1.074$ & 0.003 \\
\hline Lymphocytes rate & 0.971 & $0.956-0.985$ & $<0.001$ \\
\hline \multicolumn{4}{|l|}{ Chronic diseases } \\
\hline Cardiovascular disease & 1.180 & $0.855-1.628$ & 0.314 \\
\hline Hyperlipidemia & 1.108 & $0.859-1.431$ & 0.429 \\
\hline Diabetes & 1.233 & $0.933-1.629$ & 0.141 \\
\hline Atrial fibrillation & 1.390 & $0.925-1.885$ & 0.134 \\
\hline COPD & 1.012 & $0.746-1.372$ & 0.939 \\
\hline CKD & 1.565 & $0.988-1.983$ & 0.066 \\
\hline Stroke & 1.721 & $0.985-3.008$ & 0.056 \\
\hline Malignancy & 1.306 & $0.858-1.989$ & 0.213 \\
\hline 3 or more comorbidities & 1.322 & $1.034-1.692$ & 0.026 \\
\hline \multicolumn{4}{|l|}{ Chronical drugs intake } \\
\hline $\mathrm{ACEi}$ & 0.993 & $0.775-1.273$ & 0.956 \\
\hline $\mathrm{ARBs}$ & 0.771 & $0.584-1.019$ & 0.068 \\
\hline $\mathrm{CCBs}$ & 0.951 & $0.736-1.229$ & 0.702 \\
\hline Alpha blockers & 1.180 & $0.797-1.746$ & 0.410 \\
\hline Diuretics & 1.466 & $1.003-1.882$ & 0.063 \\
\hline Beta blockers & 1.171 & $0.916-1.497$ & 0.207 \\
\hline
\end{tabular}

$\mathrm{HR}$ hazard ratio, $\mathrm{PaO} 2 / \mathrm{FiO} 2$ partial pressure of oxygen in arterial blood/fraction of inspired oxygen, $L D H$ lactate dehydrogenase, $C O P D$ chronic obstructive pulmonary disease, $C K D$ chronic kidney disease, $A C E i$ angiotensin-converting enzyme inhibitors, $A R B s$ angiotensin-receptor blockers, $C C B s$ calcium-channel blockers

some experts have postulated that use of ACEi/ARBs could increase risk for or severity of COVID-19, suggesting the withdrawal of these drugs [17]. The second hypothesis highlights the protective role of ACE2 on lung injury by reducing angiotensin II level. It has been postulated that unabated angiotensin II may be in part responsible for organ injury in COVID-19 [15], suggesting potential for benefit rather than harm of pharmacological regulation of ACE2 expression. Both hypotheses are based on few data, and observational studies have not yielded compelling data on whether COVID-19 patients who take these drugs fare better or worse than otherwise similar patients. Experimental animal models and studies in humans have shown mixed findings with respect to the effects of RAS inhibition on ACE2 levels or activity in tissue. Unfortunately, data regarding the effects of RAS inhibitors on lung-specific expression of ACE2 are

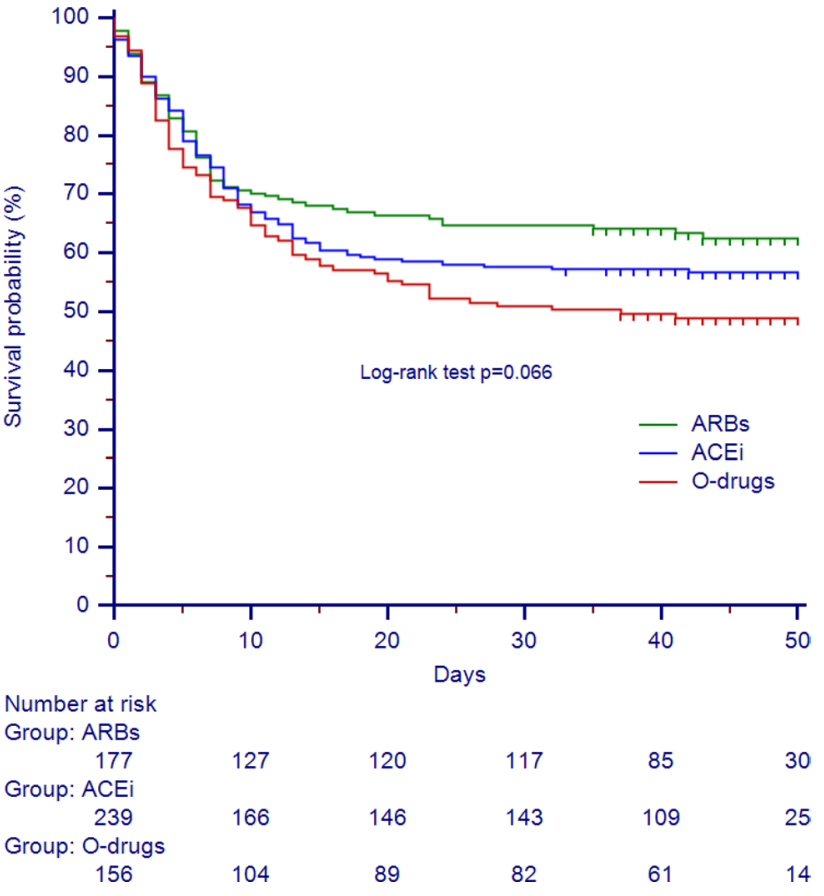

Fig. 1 Kaplan-Meier event curves reported the mortality between groups stratified by the antihypertensive drug treatment. No differences between ARBs, ACEi or O-drugs treatment were found. ARBs angiotensin-receptor blockers, $A C E i$ angiotensin converting enzyme inhibitors, O-drugs other drugs, including Beta-blockers, Calcium channels blockers, Alfa-blockers, and Diuretics

lacking. Recently, Zhang et al. [18] reported the outcomes of hospitalized COVID-19 patients with HTN stratified by RAS inhibitors in-hospital intake. In this retrospective inpatient study, use of ACEi/ARBs was associated with lower risk of all-cause mortality compared with ACEi/ARBs non-users. Feng Y et al. [19] found a significant difference in ACEi/ ARBs usage among COVID-19 patients with different severities, according to the Chinese guidelines on diagnosis and treatment of COVID-19. Our findings were consistent with these results: the use of ACEi or ARBs was not associated with a detrimental effect on mortality, as compared with patients treated with other antihypertensive drugs.

\section{Clinical implications}

Despite the theoretical uncertainties regarding whether RAS inhibition may influence the infectivity of SARSCoV-2, there are few available evidences about switching from a RAS inhibitor to another antihypertensive therapy in patients with known or suspected COVID-19. Moreover, a high number of HTN patients solicited therapy changes or interruption during on-going pandemic. Changes in antihypertensive drug treatment require dose titration and potentially exposes patients to the side effects related to the 


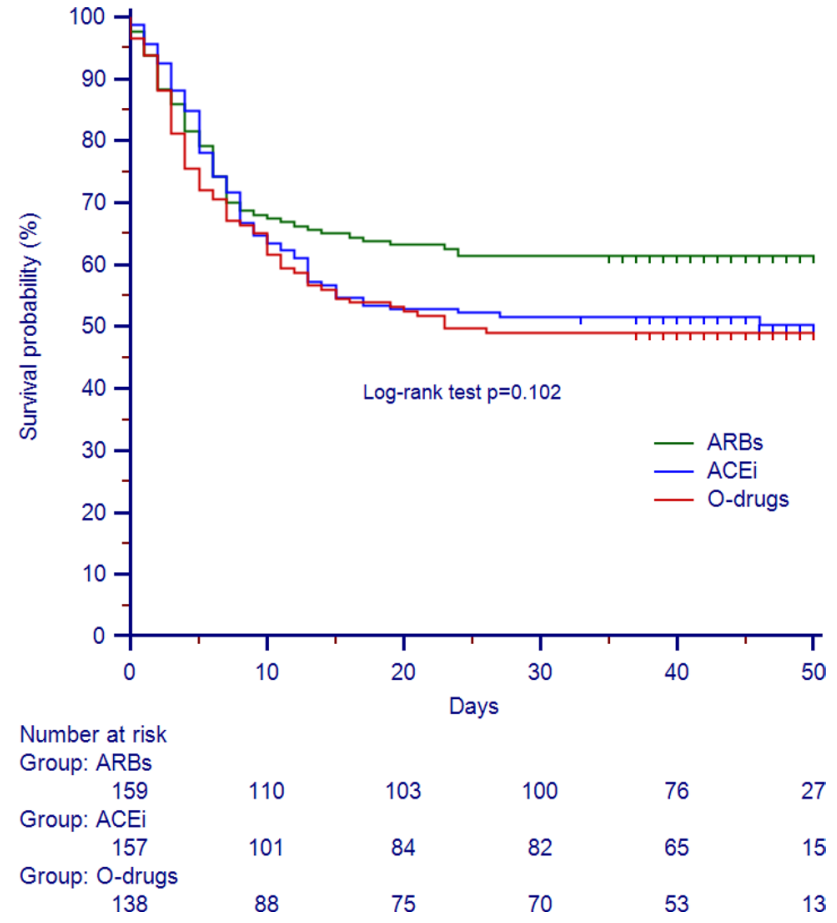

Fig. 2 Kaplan-Meier event curves reported the mortality between propensity score-matched groups stratified by the antihypertensive drug treatment. No differences between groups were found. ARBs angiotensin-receptor blockers, $A C E i$ angiotensin converting enzyme inhibitors, $\mathrm{O}$-drugs other drugs, including Beta-blockers, Calcium channels blockers, Alfa-blockers, and Diuretics

new regimen; the risk of SARS-CoV-2 exposure related to the transient lockdown interruption for face-to-face visits should not be neglected. Accordingly, several Specialty Societies strongly recommended to continue RAS inhibitors in patients in otherwise stable condition who are at risk for, are being evaluated for, or have COVID-19. Our data confirm this statement, suggesting that treatment with ACEi or ARBs should not be discontinued because of COVID-19.

\section{Strengths and limitations}

This study was a retrospective observational analysis of data from a Hospital Network of a single Province in Italy. It is plausible that the effects of ACEi/ARBs may be different among patients in ethnically or geographically diverse populations. Moreover, we did not account for socioeconomic status. However, large sample size with absence of missing values for collected variables and long-term followup is a major strength. Since the study was underpowered to detect any differential effect between ACEi and ARBs, future bigger observational studies and on-going prospective randomized trials are advisable to fully elucidate possible protective effects of those drug treatments [20-23].

\section{Conclusions}

In summary, in patients with hypertension, AngiotensinConverting Enzyme inhibitors and Angiotensin-Receptor Blockers are not associated with mortality of COVID-19. Our data confirm Specialty Societal recommendations, suggesting that treatment with renin-angiotensin system inhibitors should not be discontinued or replaced with other antihypertensive drugs because of COVID-19.

\section{Compliance with ethical standards}

Conflict of interest The authors report no conflicts.

\section{References}

1. WHO. Novel coronavirus-China. Jan 12, 2020. 2020; https:// www.who.int/csr/don/12-january-2020-novel-coronavirus-china /en/. Accessed 15 April 2020.

2. WHO. Director-General's opening remarks at the media briefing on COVID-19: 11 March 2020. Published March 11, 2020. 2020; https://www.who.int/dg/speeches/detail/who-director-gener al-s-opening-remarks-at-the-media-briefing-on-COVID-19---11march-2020. Accessed 16 April 2020.

3. Huang C, Wang Y, Li X, Ren L, Zhao J, Hu Y, et al. Clinical features of patients infected with 2019 novel coronavirus in Wuhan, China. Lancet. 2020;395:497-506.

4. Wang D, Hu B, Hu C, Zhu F, Liu X, Zhang J, et al. Clinical Characteristics of 138 hospitalized patients with 2019 novel coronavirus-infected Pneumonia in Wuhan, China. JAMA. 2020;323:1061-9.

5. Hoffmann M, Kleine-Weber H, Schroeder S, Krüger N, Herrier T, Erichsen S, et al. SARS-CoV-2 cell entry depends on ACE2 and TMPRSS 2 and is blocked by a clinically proven protease inhibitor. Cell. 2020;181:271-80.

6. WHO. Clinical management of severe acute respiratory infection when novel coronavirus $(\mathrm{nCoV})$ infection is suspected: interim guidance. January 28, 2020. 2020. Accessed 5 March 2020.

7. Williams B, Mancia G, Spiering W, Agabiti Rosei E, Azizi M, Burnier M, et al. 2018 ESC/ESH guidelines for the management of arterial hypertension. J Hypertens. 2018;36:1953-2041.

8. National Health Commission of the People's Republic of China Diagnosis and treatment protocol for COVID-19 (trial version 7) 2020. https://www.chinadaily.com.cn/pdf/2020/1.Clinical.Proto cols.for.the.Diagnosis.and.Treatment.of.COVID-19.V7.pdf.

9. Guan WJ, Ni ZY, Hu Y, Liang WH, Ou CQ, He JX, et al. Clinical characteristics of coronavirus disease 2019 in China. N Engl J Med. 2020;382:1708-20.

10. Lu J, Lu Y, Wang X, Li X, Linderman GC, Wu C, et al. Prevalence, awareness, treatment, and control of hypertension in China: data from 1.7 million adults in a population-based screening study (China PEACE Million Persons Project). Lancet. 2017;390:2549-58.

11. Messerli FH, Bangalore S, Bavishi C, Rimoldi SF. Angiotensinconverting enzyme inhibitors in hypertension: to use or not to use? J Am Coll Cardiol. 2018;71:1474-82.

12. Potier L, Roussel R, Elbez Y, Marre M, Zeymer U, Reid CM, et al. Angiotensin-converting enzyme inhibitors and angiotensin receptor blockers in high vascular risk. Heart. 2017;103:1339-46. 
13. Khan A, Benthin C, Zeno B, Albertson TE, Boyd J, Christie JD, et al. A pilot clinical trial of recombinant human angiotensinconverting enzyme 2 in acute respiratory distress syndrome. Crit Care. 2017;21:234.

14. Ishiyama Y, Gallagher PE, Averill DB, Tallant EA, Brosnihan KB, Ferrario CM. Upregulation of angiotensin-converting enzyme 2 after myocardial infarction by blockade of angiotensin II receptors. Hypertension. 2004;43:970-6.

15. Zhang H, Penninger JM, Li Y, Zhong N, Slutsky AS. Angiotensinconverting enzyme 2 (ACE2) as a SARS-CoV-2 receptor: molecular mechanisms and potential therapeutic target. Intensive Care Med. 2020;46:586-90.

16. Kuba K, Imai Y, Rao S, Gao H, Guo F, Guan B, et al. A crucial role of angiotensin converting enzyme 2 (ACE2) in SARS coronavirus-induced lung injury. Nat Med. 2005;11:875-9.

17. Sommerstein R, Kochen MM, Messerli FH, Grani C. Coronavirus disease 2019 (COVID-19): do angiotensin-converting enzyme inhibitors/angiotensin receptor blockers have a biphasic effect? J Am Heart Assoc. 2020;9:e016509.

18. Zhang P, Zhu L, Cai J, Lei F, Qin JJ, Xie J, et al. Association of inpatient use of angiotensin converting enzyme inhibitors and angiotensin II receptor blockers with mortality among patients with hypertension hospitalized with COVID-19. Circ Res. 2020;126:1671-81.
19. Feng Y, Ling Y, Bai T, Xie Y, Huang J, Li J, et al. COVID-19 with different severity: a multi-center study of clinical features. Am J Respir Crit Care Med. 2020;201:1380-8.

20. Lopes RD, Macedo AV, Melo de Barros e Silva PG, JunqueiraMoll-Bernardes R, Feldman A, SabaArruda GD, et al. Continuing versus suspending angiotensin-converting enzyme inhibitors and angiotensin receptor blockers: impact on adverse outcomes in hospitalized patients with severe acute respiratory syndrome coronavirus 2 (SARS-CoV-2) - The BRACE CORONA Trial. Am Heart J. 2020;226:49-59.

21. ClinicalTrials.gov. Coronavirus (COVID-19) ACEi/ARB investigation (CORONACION). ClinicalTrials.gov identifier: NCT04330300. https://clinicaltrials.gov/ct2/show/NCT0433030 0 . Accessed 10 June 2020.

22. ClinicalTrials.gov. ACE inhibitors or ARBs discontinuation in context of SARS-CoV-2 pandemic (ACORES-2). ClinicalTrials. gov identifier: NCT04329195. https://clinicaltrials.gov/ct2/show/. Accessed 10 June 2020.

23. ClinicalTrials.gov. Losartan for patients with COVID-19 not requiring hospitalization. ClinicalTrials.gov identifier: NCT04311177. https://clinicaltrials.gov/ct2/show/NCT0431117 7. Accessed 10 June 2020. 